\title{
AGGREGATE-SCALE HETEROGENEITY IN IRON (HYDR)OXIDE REDUCTIVE TRANSFORMATIONS
}

Katharine J. Tufano, Shawn G. Benner, Klaus U. Mayer, Matthew A. Marcus, Peter S. Nico, and Scott Fendorf ${ }^{1 *}$

K.J. Tufano and S. Fendorf, School of Earth Sciences, Stanford Univ., Stanford, CA 94305;

S.G. Benner, Dept. of Geosciences, Boise State Univ., Boise, ID 83725;

K.U. Mayer, Dept. of Earth and Ocean Sciences, Univ. of British Columbia, Vancouver, B.C. V6T 1Z4 Canada; M.A. Marcus, Advanced Light Source, Lawrence Berkeley National Laboratory, Berkeley, CA 94720;

P.S. Nico, Earth Sciences Division, Lawrence Berkeley National Laboratory, Berkeley, CA 94720. 


\begin{abstract}
There is growing awareness of the complexity of potential reaction pathways and the associated solid-phase transformations during the reduction of iron (hydr)oxides, especially ferrihydrite. An important observation in static and advective-dominated systems is that microbially-produced $\mathrm{Fe}(\mathrm{II})$ accelerates Ostwald ripening of ferrihydrite, thus promoting the formation of thermodynamically more stable ferric phases (lepidocrocite and goethite) and, at higher Fe(II) surface loadings, the precipitation of magnetite- - high Fe(II) levels can also lead to green rust formation, and with high carbonate levels siderite may also be formed. This work expands this emerging conceptual model to a diffusion-dominated system that mimics an idealized micropore of a ferrihydrite-coated soil aggregate undergoing reduction. Using a novel diffusion cell, coupled with micro-X ray fluorescence and absorption spectroscopies, we reveal that diffusion-controlled gradients in $\mathrm{Fe}^{2+}{ }_{(\mathrm{aq})}$ result in a complex array of spatially distributed secondary mineral phases. At the diffusive pore entrance, where $\mathrm{Fe}^{2+}$ concentrations are highest, green rust and magnetite are the dominant secondary iron (hydr)oxides (30 mole \% Fe each). At intermediate distances from the inlet, green rust is not observed and the proportion of magnetite decreases from approximately 30 to $<10 \%$. Over this same transect, the proportion of goethite increases from undetectable up to $>50 \%$. At greater distances from the advective-diffusive boundary goethite is the dominant phase, comprising between $40-95 \%$ of the iron. In the presence of magnetite, lepidocrocite forms as a transient-intermediate phase during ferrihydriteto-goethite conversion; in the absence of magnetite, conversion to goethite is more limited. These experimental observations, coupled with results of reactive transport modeling, confirm the conceptual model and illustrate the potential importance of diffusion-generated concentration gradients in dissolved $\mathrm{Fe}^{2+}$ on the fate of ferrihydrite during reduction in structured soils.
\end{abstract}




\section{INTRODUCTION}

While ubiquitous in the environment, commonly as coatings on fractures or soil particles, iron (hydr)oxides often comprise only a small proportion of the total solid phase in soils and sediments. Nevertheless, cycling of iron (hydr)oxides can exert a dominant control on nutrient and contaminant mobility and bioavailability due to their large surface areas and high reactivity; iron (hydr)oxides can bind a wide-range of organic and inorganic constituents (e.g. carbon tetrachloride, arsenic, and phosphate) (Cornell and Schwertmann, 2003). Accordingly, dissolution and transformation of iron (hydr)oxides can have major implications for the fate and transport of nutrients and trace element contaminants in both saturated and unsaturated environments (Bekins et al., 2001; DeLemos et al., 2006; Salminen et al., 2006); concomitant with the dissolution (inclusive of transformation) of iron (hydr)oxides, adsorbed or coprecipitated nutrients (or contaminants) may be mobilized, or reductively immobilized (Tokunaga et al., 2001; Tokunaga et al., 2005).

Under oxidizing conditions, ferric-bearing minerals predominate as sparingly soluble phases such as ferrihydrite, goethite and hematite. In soils and sediments, poorly crystalline iron (hydr)oxides such as ferrihydrite are often the first phases to form, but are thermodynamically unstable and transform over time into more crystalline/stable forms such as goethite and hematite (Steefel and Van Cappellen, 1990; Cornell and Schwertmann, 2003; Kukkadapu et al., 2003). Upon initiation of reducing conditions, often induced by increased water saturation, dissimilatory iron-reducing bacteria (DIRB) couple the oxidation of organic matter or hydrogen with the reduction of iron (hydr)oxides (Gorby and Lovley, 1991; Nealson and Saffarini, 1994; Roden and Zachara, 1996; Lovley, 1997), releasing $\mathrm{Fe}^{2+}$ to the pore water. There is emerging evidence that the produced $\mathrm{Fe}(\mathrm{II})$, albeit a product of many contributing/competing biotic and abiotic 
processes, plays a major role in promoting transformation of iron (hydr)oxides to more stable and insoluble iron-bearing mineral phases (Fredrickson et al., 1998; Benner et al., 2002; Zachara et al., 2002; Hansel et al., 2003; Hansel et al., 2005; Pedersen et al., 2006). Dissolved ferrous iron influences iron (hydr)oxide transformations in two important ways. First, Fe(II) adsorption and electron transfer to structural Fe(III) enhances the rate of iron (hydr)oxide dissolution, thereby promoting Ostwald ripening (Cornell and Schwertmann, 2003). Second, the presence of dissolved $\mathrm{Fe}^{2+}$ makes precipitation of $\mathrm{Fe}(\mathrm{II})$-bearing mineral phases feasible, provided they are thermodynamically favorable and kinetically viable. Ferrous iron promotes dissolution and transformation of ferrihydrite (Fig. 1) to goethite and lepidocrocite through a dissolutionreprecipitation mechanism and formation of magnetite through heterogeneous nucleation and precipitation—green rust is formed through homogeneous nucleation and precipitation. Elevated aqueous $\mathrm{Fe}^{2+}$ can also promote precipitation of siderite and vivianite in the presence of locally high concentrations of bicarbonate or phosphate, respectively (Postma, 1981; Fredrickson et al., 1998; Zachara et al., 2002; Borch et al., 2007).

Within soils, the fate of iron oxides will be influenced by physical heterogeneity which has a dominant influence on the local biogeochemical conditions. Soils are a composite of chemical and biological constituents that develop within a framework of intricate physical structure consisting of various pore-sizes, conductivity, and connectivity across a wide range of scales (Fig. 2) and moisture contents. Within this natural physical heterogeneity, larger pores are more likely to support advective transport while transport through smaller, micropores (Marshall, 1959; Johnson et al., 1960; Luxmoore, 1981) will more likely be diffusive in nature (Wilson et al., 1992; Harvey and Nuttle, 1995; Bai and Roegiers, 1997). Heterogeneity in physical transport can result in drastic variations in biogeochemical processes (Parkin, 1987; Brzezinska et al., 
1998; Tokunaga et al., 2001; Tokunaga et al., 2004); this heterogeneity in biogeochemical processes influences the distribution of iron (hydr)oxide minerals, and potentially, the fate and transport of associated nutrients and trace metal contaminants (Bai and Roegiers, 1997).

Because larger pores can support both higher influxes of needed nutrients and efflux of reaction products, they have the potential to sustain higher levels of microbial activity (Bundt et al., 2001). In contrast, within micropores, diffusive constraints will limit reaction progress. With active microbial reduction likely to be higher in macropores or isolated carbon 'hot spots', transformation of iron (hydr)oxides in micropores may be controlled by diffusive transport of $\mathrm{Fe}(\mathrm{II})$ from regions of sustained microbial Fe(III) reduction.

Geochemical controls governing the extent, rate and mechanisms of iron (hydr)oxide transformations in well mixed or static batch experiments and under advective flow have been extensively investigated (Benner et al., 2002; Zachara et al., 2002; Hansel et al., 2003); however, applicability of much of these data in physically complex systems has not yet been tested. Accordingly, here we examine the impact of a diffusion-induced gradient in $\mathrm{Fe}^{2+}$ (aq) on the mineral phase transformation of ferrihydrite. Our results document the creation of a complex, spatially and temporally distributed, array of secondary mineral phases, highlighting the potential importance of diffusive gradients in dictating the fate of iron during reduction of structured soils.

\section{MATERIALS AND METHODS}

\section{Experimental Methods}

We examined the impact of diffusive gradients on Fe(II)-induced transformation of ferrihydrite within parallel plate reaction cells. Unless otherwise specified, all experiments were performed in an anaerobic chamber (Coy Laboratories, Inc., Grass Lakes, MI) with a $\mathrm{N}_{2}(95 \%): \mathrm{H}_{2}(5 \%)$ 
atmosphere. Anaerobic solutions were prepared using water that had been boiled and cooled under a stream of $\mathrm{O}_{2}$-free $\mathrm{N}_{2}$ gas. Ferrihydrite was synthesized according to Schwertmann and Cornell (1991). A thin layer of ferrihydrite was painted onto the surface of a lexan slide and allowed to air dry. A final iron concentration of $1.15 \mathrm{mg} \mathrm{Fe} \mathrm{cm}^{-2}$ lexan surface area (total surface area of $18.75 \mathrm{~cm}^{2}$; ferrihydrite coated surface area of $5.13 \mathrm{~cm}^{2}$ ) was obtained using this technique. The ferrihydrite coated lexan was then overlain with a glass plate (Fisherbrand SuperFrost microscope slides) and the two long, parallel edges sealed with silicon adhesive (Fig. 3), attaining a final volume of $0.12 \mathrm{~cm}^{3}$. Prior to the experiment, the ferrihydrite coated parallel plate system was transferred to the anaerobic chamber and suspended in a solution of $\mathrm{O}_{2}$-free 16 mM PIPES solution buffered at $\mathrm{pH}$ 7.1. The parallel plate system was then transferred to a beaker containing $25 \mathrm{~mL}$ of $40 \mathrm{mM}$ ferrous sulfate solution (also buffered with $16 \mathrm{mM}$ PIPES), allowing only one end of the parallel plates to be submerged in solution. A concentration of 40 $\mathrm{mM}$ ferrous sulfate was used to provide a steep gradient across the reaction cell, allowing the rapid development of a $\mathrm{Fe}^{2+}$ driven transformation gradient. While bulk aqueous $\mathrm{Fe}^{2+}$ concentrations are rarely this high in natural systems, concentrations within a reactive microniche where $\mathrm{Fe}^{2+}$ is actively generated may reach these levels. Three identical parallel plate systems were left to react for $21 \mathrm{~d}$. Upon termination of the experiment, the plates were removed from the reactant solutions, drained, rinsed with DDI water, and allowed to dry inside the anaerobic chamber. Reacted systems were then disassembled, leaving only the iron (hydr)oxide coated lexan surface, which was then sealed between two pieces of Kapton polyamide film tape to prevent oxidation. Upon visual examination, replicate plates showed very similar iron (hydr)oxide distributions; however, due to the limited availability of $\mu$-XAS synchrotron time, these additional plates were not able to be analyzed. 


\section{Analytical Methods}

The speciation and distribution of Fe phases was determined using micro-X-ray absorption spectroscopy ( $\mu$-XAS). Micro-XAS analyses were conducted at beamline 10.3 .2 at the Advanced Light Source (ALS), Lawrence Berkeley National Laboratory. Energy selection was accomplished using a water cooled $\mathrm{Si}$ (111) monochromator, and spectra were recorded by fluorescent X-ray production. The X-ray beam was focused to approximately $5 \mu \mathrm{m}$ (horizontal) by $5 \mu \mathrm{m}$ (vertical). Maps of Fe speciation were obtained by scanning (20 $\mu \mathrm{m}$ steps) a $1 \mathrm{~mm}$ x 10 $\mathrm{mm}$ region of the reacted plate at $7106,7114,7123,7132,7134$ and $7145 \mathrm{eV}$. Iron maps were taken at $7106 \mathrm{eV}$ to determine background iron fluorescence; other energies were selected based on the presence of characteristic features (determined from examination of EXAFS of each iron (hydr)oxide) that can be used to definitively distinguish individual iron (hydr)oxides. At each pixel, the set of fluorescence intensities measured at the six energies listed above can be thought of as a coarsely-tabulated XAS spectrum, which was then fit to reference spectra in order to determine the fractions of the different species at the given pixel location. The use of more energies than reference species provides a consistency check and a measure of redundancy. Using this technique, the distribution of iron (hydr)oxides across the surface of the parallel plate could be determined.

Extended X-ray absorption fine structure (EXAFS) spectra were collected from -200 to $+500 \mathrm{eV}$ about the $\mathrm{K}$-edge of $\mathrm{Fe}$ at select locations using the same beam size. The XAS analytical procedure used here were similar to those described previously (Hansel et al, 2003). EXAFS spectra were collected on a $3 \times 9$ grid on the reacted iron (hydr)oxide coating with three spectra spaced ca. $300 \mu \mathrm{m}$ apart taken across the width of the parallel plate and repeated at 9 
distances along the length of the parallel plate moving away from the inlet. The XAS analytical procedure used here was similar to those described previously (Hansel et al, 2003). EXAFS spectra were extracted from the averaged data files by pre-edge subtraction followed by spline fitting using SixPack (Webb, 2005). Background-subtracted $\mathrm{k}^{3}$-weighted EXAFS were analyzed using the SixPack interface to IFEFFIT (Newville, 2001) and fit in the k-range 3 to $10.5 \AA^{-1}$. Linear combination of model compounds was performed to reconstruct unknown spectra. A set of Fe reference compounds was used to perform linear combination $k^{3}$-weighted EXAFS spectral fitting; linear combinations of the reference compounds were optimized and the only variable parameters were the fractions of each reference compounds. Reference compounds were chosen based on their likelihood of being a reaction product (including, for example, criteria such as elemental composition), and were included in the fit only if they contributed with a fraction of 0.05 or more. Detection limit for minor constituents is approximately 5\%, as described previously (Hansel et al, 2003). The set of Fe reference standards included ferrihydrite, goethite, lepidocrocite, magnetite, green rust-sulfate, siderite and vivianite. Each of these oxides were synthesized following the procedures of Schwertmann and Cornell (1991) and verified using Xray diffraction (XRD) analysis. Linear combination fits of EXAFS spectra at triplicate points across the width of the parallel plate were averaged and a single distribution of iron (hydr)oxide was calculated and determined to be representative of a particular distance from the parallel plate inlet.

\section{Modeling}

Simulations were performed using MIN3P (Mayer et al., 2002), a general purpose reactive transport code that has previously been used for the investigation of a variety of reactive 
transport problems in saturated and unsaturated porous media (Mayer et al., 2002; Jurjovec et al., 2004). The MIN3P code couples advective-diffusive flow, solute transport, intra-aqueous reactions and solid phase transformations.

To evaluate the conceptual model of our experiment, we translated that conceptualization into a physical-chemical reaction network capable of reproducing the mineral phase transformations observed both in previously published batch reactions (Hansel et al., 2005) (Fig. 4) and the diffusion reaction cell described here (Fig. 5). The modeling approach utilizes thermodynamic constants to limit reaction progress to conditions under which each reaction is thermodynamically favored and links that constraint to empirically based rate expressions derived to match observed trends in the experimental data. In these experimental systems variable initial conditions exist including: aqueous $\mathrm{Fe}^{2+}$ concentrations, amount of solid phase ferrihydrite, and static versus diffusion-driven mass transfer. Observation has documented the resulting change in mineral phase distribution in space and time providing considerable constraint on the calibrated reaction rate expressions. The goal of the modeling was to develop a series of reaction rate expressions that can simulate the different mineral phase changes induced by the change in initial conditions. Accordingly, the simulations of each set of observational data used identical chemical reaction networks incorporating the same reaction rate expressions. The batch and diffusion reaction cell simulations vary only with respect to initial conditions, physical framework and dimensionality; rate expressions are identical for all the simulations. Thus, the degree to which the model output matches the disparate experimental observations is a primarily a measure of the robustness of the conceptual model, especially with respect to changing $\mathrm{Fe}^{2+}$ concentrations and static versus diffusion driven mass transfer conditions. 
The batch reactions were simulated as zero-dimensional domain with a fixed uniform volume $(0.0135 \mathrm{~g}$ Fe in $125 \mathrm{~mL})$ over time $(6 \mathrm{~d})$. In contrast, the diffusion reaction cell was idealized within the model as a one-dimensional $(5 \mathrm{~cm}$ long) domain assuming a parallel plate volume of $0.12 \mathrm{~cm}^{3}$ and a uniform ferrihydrite surface coating area of $5.13 \mathrm{~cm}^{2}$. The inlet boundary was defined as a fixed concentration boundary $\left(40 \mathrm{mM} \mathrm{Fe}{ }^{2+}\right.$ and $\left.\mathrm{SO}_{4}{ }^{2-}\right)$; the distal boundary was assumed impermeable (zero-concentration gradient). Accordingly, mass transfer was simulated by diffusive transport assuming a common diffusion coefficient for all species of $10^{-9} \mathrm{~m}^{2} \mathrm{~s}^{-1}$ (Sobolev and Roden, 2001; Neubauer et al., 2002). Simulations were allowed to run for a reaction time of $21 \mathrm{~d}$.

The reaction network was developed around the experimentally observed dissolution and precipitation transformations and it includes the aqueous complexation reactions that affect mineral solubility. Aqueous complexation reactions are treated as equilibrium reactions based on reaction constants in the MINTEQA2 database. The solid phase transformations (ferrihydrite, lepidocrocite, goethite, and magnetite) were treated as kinetic reactions while honoring thermodynamic solubility constraints (Table 1).

Experimental observations suggest that the reductive transformation of ferrihydrite involves a number of threshold-type changes that can dramatically alter the reaction pathway. The first is best evidenced in Hansel et al (2003), who demonstrated an aqueous $\mathrm{Fe}^{2+}$ concentration threshold $\left(0.3 \mathrm{mmol} \mathrm{L}^{-1}\right.$, for this system $)$, above which magnetite is observed as a secondary phase and below which goethite or lepidocrocite is produced. The mechanistic reason for this threshold likely involves the nucleation energy for magnetite but at present is not fully resolved. Similarly, as indicated in Hansel et al (2005) and shown in Fig. 4, the accumulation of magnetite appears to promote the re-dissolution of lepidocrocite/goethite. Finally, there is an 
apparent limit on the amount of ferrihydrite that is reactive; a residual of approximately $20 \%$ of the original volume remains unreacted in all experiments. We have chosen to express thresholds using a similar, but purely empirical, hyperbolic-based formulation that provides the appropriate influence on the rate expression; these rate terms are described in detail below.

Ferrihydrite dissolution was expressed as:

$$
\mathrm{Fe}(\mathrm{OH})_{3}+3 \mathrm{H}^{+} \Rightarrow \mathrm{Fe}^{3+}+3 \mathrm{H}_{2} \mathrm{O}
$$

The rate of ferrihydrite dissolution (note the thermodynamic driving force) was enhanced by the presence of ferrous iron with previously observed dependency of $\left[\mathrm{Fe}^{2+}\right]^{0.5}$ (Fischer, 1972; Cornell and Schwertmann, 2003). It was also assumed that dissolution can only occur when the simulated aqueous solution is under-saturated; as thermodynamic equilibrium is reached in the simulation, dissolution must cease. This dependency can be expressed by the relationship between the model-produced ion activity product (IAP) and the published solubility product $\left(K_{s p}\right)$ (Steefel and Van Cappellen, 1990). Finally, in both the batch and diffusion cell experiments, a fraction of the initial ferrihydrite was non-reactive; this threshold behavior is reproduced using an empirical hyperbolic term similar to a Monod formulation. Consequently, the rate of ferrihydrite dissolution is expressed as:

$$
R_{\text {ferri-diss }}=-k_{\text {ferri-diss }} \max \left(0,\left[1-\frac{I A P_{\text {ferri }}}{K_{s p(\text { ferri })}}\right]\right)\left(\frac{[\text { Ferri }]}{K_{\text {ferri-diss }}^{\text {thres }}+[\text { Ferri }]}\right)^{X}\left[F e^{2+}\right]^{0.5}
$$

where $k_{\text {ferri-diss }}$ is the effective rate coefficient established by model calibration to be $5.0 \mathrm{~mol}^{0.5}$ $\mathrm{dm}^{-3} \mathrm{~L}^{0.5} \mathrm{~s}^{-1}, I A P_{\text {ferri }}$ is the solution ion activity product for ferrihydrite, $K_{s p(f e r r i)}$ is the solubility product for ferrihydrite (Table 1), and $K_{\text {ferri-diss }}^{\text {thres feri }}$ is the threshold volumetric concentration below which the rate of ferrihydrite dissolution is strongly retarded; it is fixed at $20 \%$ of the initial solid phase present. The exponent term (x) equals 16 . Note that the IAP- $\mathrm{K}_{\mathrm{sp}}$ term approaches zero as 
equilibrium is reached, driving the dissolution rate to zero. In contrast, when far from equilibrium, the IAP-K $\mathrm{K}_{\mathrm{sp}}$ term reduces to 1 , and the dissolution rate is controlled by the other rate terms. Ferrihydrite precipitation was not observed in the experiments and was not included in the model.

Goethite and lepidocrocite precipitation and dissolution were expressed as:

$$
\mathrm{Fe}^{3+}+2 \mathrm{H}_{2} \mathrm{O} \Leftrightarrow \mathrm{FeOOH}+3 \mathrm{H}^{+}
$$

As with ferrihydrite, goethite dissolution and precipitation rates decrease as equilibrium is approached. Standard rate expressions that are derived based on combining dissolution and precipitation reactions into a single rate expression (Stumm and Morgan, 1996) lead to unrealistically large precipitation rates under highly supersaturated conditions. Accordingly, the reaction rates for goethite precipitation and dissolution are decoupled and expressed as:

$$
\begin{aligned}
& R_{\text {goeth-pptn }}=k_{\text {goeth-pptn }} \max \left(0,\left[1-\frac{K_{s p(\text { goeth })}}{I A P_{\text {goeth }}}\right]\right) \\
& R_{\text {goeth-diss }}=-k_{\text {goeth-diss }} \max \left(0,\left[1-\frac{I A P_{\text {goeth }}}{K_{s p(\text { goeth })}}\right]\right)
\end{aligned}
$$

where $k_{\text {goeth-diss }}, k_{\text {goeth-pptn }}$ are the effective rate coefficients for goethite dissolution and precipitation, respectively. These values are established by model calibration to be $1 \times 10^{-6}$ and 1 x $10^{-7} \mathrm{~mol} \mathrm{dm}^{-3} \mathrm{~s}^{-1}$, respectively. The term $I A P_{\text {goeth }}$ is the modeled solution ion activity product for goethite and the term $K_{s p(g o e t h)}$ is the solubility product for goethite (Table 1), and the coupling of these terms dictate that the overall rate of dissolution (or reprecipitation) reduces to zero as equilibrium is approached (i.e., when IAP $=\mathrm{K}_{\mathrm{sp}}$ ). When the system is far from equilibrium, the IAP-K $\mathrm{K}_{\mathrm{sp}}$ term approaches unity and the entire rate expression collapses to a zero order rate equation. 
Lepidocrocite precipitation and dissolution rates are formulated similarly to goethite with a decoupling of the precipitation and dissolution rates. However, the batch experiments indicate that the dissolution of lepidocrocite is strongly influenced by the presence of elevated $\mathrm{Fe}^{2+}$ concentrations and/or the accumulation of magnetite. Accordingly, the dissolution of lepidocrocite includes both a $\left[\mathrm{Fe}^{2+}\right]$ dependency term and threshold dependency term on magnetite presence:

$$
\begin{gathered}
R_{\text {lepido-pptn }}=k_{\text {lepido-pptn }} \max \left(0,\left[1-\frac{K_{\text {sp(lepido) }}}{I A P_{\text {lepido }}}\right]\right) \\
R_{\text {lepido-diss }}=-k_{\text {lepido-diss }} \max \left(0,\left[1-\frac{I A P_{\text {lepido }}}{K_{\text {spplepido) }}}\right]\right)\left(\frac{[\text { Magn }]}{K_{\text {lepido-diss }}^{\text {threst }}+[\text { Magn }]}\right)\left[F e^{2+}\right]
\end{gathered}
$$

where $k_{\text {lepido-pptn }}$ and $k_{\text {lepido-diss }}$ are the effective rate coefficients established by model calibration to be $1 \times 10^{-4} \mathrm{~mol} \mathrm{dm}^{-3} \mathrm{~s}^{-1}$ and $6 \times 10^{-3} \mathrm{dm}^{-3} \mathrm{~L} \mathrm{~s}^{-1}$, respectively. The term IAP $P_{\text {lepido }}$ is the solution ion activity product for lepidocrocite, $K_{s p(l e p i d o)}$ is the solubility product for lepidocrocite (Table 1), $\left[\mathrm{Fe}^{2+}\right]$ is the solution ferrous iron concentration, $[\mathrm{Magn}]$ is the volumetric concentration of magnetite and $K_{\text {lepido-diss }}^{\text {thres }(m a n)}$ is threshold concentration at which magnetite promotes lepidocrocite dissolution, established by model calibration to be $10 \%$ of the initial molar concentration of ferrihydrite.

Magnetite precipitation is expressed as:

$$
2 \mathrm{Fe}^{3+}+\mathrm{Fe}^{2+}+4 \mathrm{H}_{2} \mathrm{O} \Rightarrow \mathrm{Fe}^{I I} \mathrm{Fe}_{2}^{I I I} \mathrm{O}_{4}+4 \mathrm{H}^{+}
$$

Magnetite precipitation in this system requires a surface loading of Fe(II) that is proportional to a dissolved ferrous iron concentrations in excess of $0.2 \mathrm{mmol} \mathrm{L}^{-1}$ (Hansel et al., 2003). The rate of magnetite formation requires an expression of the necessary $\mathrm{Fe}^{2+}$ threshold concentration; this 
dependency is also expressed using a hyperbolic term. As with goethite, the rate of magnetite precipitation is assumed to be influenced by mineral phase solubility, but unlike goethite, it is assumed that magnetite does not undergo dissolution. The rate of precipitation is expressed as:

$$
R_{m a g n-p p t n}=-k_{m a g n-p p t n} \max \left(0,\left[1-\frac{K_{s p(m a g n)}}{I A P_{\text {magn }}}\right]\right)\left(\frac{\left[F e^{2+}\right]}{K_{m a g n-p p t n}^{\text {thres }\left(F e^{2+}\right.}+\left[F e^{2+}\right]}\right)^{X}
$$

where $k_{\text {magn-pptn }}$ is the effective rate coefficient established by model calibration to be $1 \times 10^{-6}$ mol $\mathrm{dm}^{-3} \mathrm{~s}^{-1}, I A P_{m a g n}$ is the solution ion activity product for magnetite, $K_{s p(m a g n)}$ is the solubility

product for magnetite (Table 1), and $K_{m a g n-p p t h}^{t h r e s\left(\mathrm{Fe}^{2+}\right)}$ is a threshold term describing the concentration of dissolved $\mathrm{Fe}^{2+}$ required for magnetite formation; it is fixed at $2 \times 10^{-2} \mathrm{~mol} \mathrm{Fe}^{2+}$, a value consistent with previously published data (Hansel et al., 2003). This threshold term requires an exponent $(X)$ value of 3 . The solid phase distribution within the simulations was simplified by combining the ferrous-bearing phases magnetite and green rust.

\section{RESULTS AND DISCUSSION}

While advective transport results in more homogeneous chemical conditions in macropores, diffusive-limited transport can produce steep concentration gradients, conditions likely to exist in micropores of soil aggregates (Grisak and Pickens, 1980; Sudicky and Frind, 1982; Parker et al., 1994). Within the idealized micropore created by parallel plates coupled with an elevated dissolved $\mathrm{Fe}^{2+}$ boundary condition, a complex, and spatially distinct, distribution of secondary mineral phases is observed (Fig. 5). Ferrihydrite transforms to goethite and magnetite within $21 \mathrm{~d}$, with lesser amounts of green rust and lepidocrocite (Fig. 5), results similar to those observed under advective flow and in hydrostatic systems (Benner et al., 2002; Zachara et al., 2002; Hansel et al., 2003; Hansel et al., 2005). Visual transformation from reddish brown to 
black occurred in the lower 1-2 $\mathrm{mm}$ (inlet end) of the cell within the first $7 \mathrm{~d}$, while the remaining iron (hydr)oxide coating (distal end) of the parallel plates transformed to a yelloworange color similar to that of goethite and lepidocrocite. Micro-X-ray fluorescence mapping (Fig. 5A) illustrates the distribution of Fe(II) within the solids along the flow path, showing green rust forming along the first $0-0.5 \mathrm{~mm}$ of the reacted parallel plate, magnetite as the dominant iron (hydr)oxide for the subsequent $c a .2 \mathrm{~mm}$, and goethite dominating at all subsequent mapped distances. Proportions of mineral phases in the reacted parallel plate system were also determined by linear combination fitting of $\mathrm{k}^{3}$-weighted EXAFS spectra (Fig. 5B and 6). In the first $0.25 \mathrm{~mm}$, green rust and magnetite were confirmed, each composing approximately $30 \%$ (mole $\% \mathrm{Fe}$ ) of the iron (hydr)oxide coating. Between approximately 0.3 and $2.5 \mathrm{~mm}$ from the inlet, green rust ceases to be observed and the proportion of magnetite decreased from approximately $30 \%$ to less than $10 \%$. Over this transect, the proportion of goethite increases from undetectable to over $50 \%$. Beyond $2.5 \mathrm{~mm}$ from the inlet, goethite is the dominant phase, comprising between $40-95 \%$ of the iron. At distances greater than $13 \mathrm{~mm}$, lepidocrocite is also observed at proportions of up to $30 \%$.

Ferrihydrite dissolution promoted by $\mathrm{Fe}(\mathrm{II})$ leads initially to the formation of either lepidocrocite or goethite (Fig. 1) (Benner et al., 2002; Zachara et al., 2002; Hansel et al., 2003; Hansel et al., 2005). With continued reaction, and Fe(II) loadings in excess of $0.5 \mathrm{mmol} \mathrm{Kg}^{-1}$ (Hansel et al., 2003), magnetite formation occurs at the expense of both goethite and lepidocrocite. In the diffusive domain, gradients of $\mathrm{Fe}^{2+}$ (aq) also initiate these secondary mineralization pathways. Steep gradients of $\mathrm{Fe}^{2+}$ (aq) forming within diffusive domains cause ferrihydrite coatings closest to the inlet to experience the highest $\mathrm{Fe}^{2+}$ concentrations, promoting rapid and more complete transformation of ferrihydrite. Analysis of reacted iron (hydr)oxide 
coatings within diffusion zones indicates formation of $12-32 \%$ magnetite at distances up to 2.3 $\mathrm{mm}$ from the advective domain. Within this same region, however, goethite comprises up to ca. $60 \%$ (mole $\% \mathrm{Fe}$ ) of the iron (hydr)oxide coating.

Deeper within the diffusive domain $(>2 \mathrm{~mm})$, where elevated $\mathrm{Fe}^{2+}{ }_{\text {(aq) }}$ arrives gradually and is delayed through consumption by reaction with ferrihydrite closer to the inlet, the ferrihydrite transformation pathway is altered. At these locations magnetite is not observed, consistent with the initially low aqueous $\mathrm{Fe}^{2+}$ concentrations. In contrast, ferrihydrite transforms to goethite and lepidocrocite. At distances greater than $2 \mathrm{~mm}$, goethite accounts for the dominant iron (hydr)oxide within the diffusive domain, reaching a maximum accumulation at $c a .4 \mathrm{~mm}$ but occurring at sustained high concentrations across the entire diffusive domain. After $21 \mathrm{~d}$ of reaction, lepidocrocite is observed at proportions up to $20-30 \%$ only at distances greater than 13 $\mathrm{mm}$ from the inlet. Considering that lepidocrocite is meta-stable with respect to goethite, particularly in the presence of Fe(II) (Cornell and Schwertmann, 2003), observation of lepidocrocite within the diffusive domain likely indicates its recent formation and therefore, recent arrival of the diffusive front of aqueous $\mathrm{Fe}^{2+}$. Given sufficient time, however, lepidocrocite is predicted to transform to goethite through Ostwald ripening.

Model simulations of batch experiments results (Hansel et al., 2005) are able to capture the key differences induced by the primary variable of dissolved $\mathrm{Fe}^{2+}$ concentration (Fig. 4). Simulations of $0.2 \mathrm{mM} \mathrm{Fe}^{2+}$ reacting with ferrihydrite illustrate the rapid accumulation of lepidocrocite and its gradual replacement by goethite, while also reproducing the absence of magnetite. Simulations of ferrihydrite reacting with $2 \mathrm{mM} \mathrm{Fe}^{2+}{ }_{\text {(aq) }}$ produce rapid accumulation of lepidocrocite followed by goethite. This simulation also captures the subsequent accumulation of magnetite and associated rapid loss of lepidocrocite. Importantly, these 
differences are reproduced without changing any reaction rate parameters, but are rather driven by the influence of changing $\mathrm{Fe}^{2+}$ concentrations in the rate expressions.

In the diffusive simulations, identical reaction rate expressions are used while initial conditions, inclusive of $\mathrm{Fe}^{2+}$ (aq) concentrations and diffusive mass transfer vary between simulations. The simulation results demonstrate the development of steep gradients in $\mathrm{Fe}^{2+}{ }_{\text {(aq) }}$ (and $\mathrm{SO}_{4}{ }^{2-}$ ) within the diffusive domain (Fig. 7). Comparison of the simulated $\mathrm{SO}_{4}{ }^{2-}$ and $\mathrm{Fe}^{2+}$ (aq) concentration profiles after 1, 10 and $21 \mathrm{~d}$ illustrates the diffusive migration of conservative and reactive species, respectively. Because sulfate is not included in any mineral precipitation reactions within the model, it exhibits conservative behavior in the reaction cell, diffusing at a

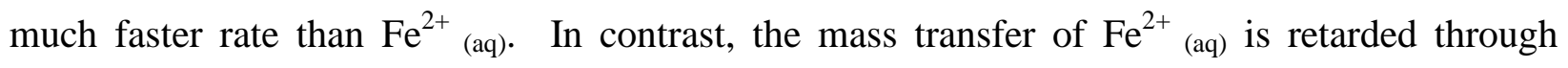
consumption by ferrihydrite transformations. Modeled Fe(II) distributions across the diffusive zone indicate that, at a distance of $20 \mathrm{~mm}$ from the advective diffusive boundary, aqueous $\mathrm{Fe}^{2+}$ concentrations are near-zero after $1 \mathrm{~d}$ of reaction. After $10 \mathrm{~d}$ of reaction, $\mathrm{Fe}^{2+}{ }_{\text {(aq) }}$ concentrations are more than an order of magnitude lower $(1.5 \mathrm{mM})$ than that measured at the advectivediffusive boundary $(40 \mathrm{mM})$, and even after $21 \mathrm{~d}, \mathrm{Fe}^{2+}{ }_{(\text {aq })}$ concentrations have only increased marginally to $2.1 \mathrm{mM}$.

Using the predicted distribution of $\mathrm{Fe}^{2+}$ (aq) within the diffusive zone after $21 \mathrm{~d}$, the simulations predict ferrihydrite transformation to predominantly magnetite (and green rust) in regions $0-2 \mathrm{~mm}$ from the advective-diffusive (AD) boundary, mixed magnetite and goethite in the region $2-10 \mathrm{~mm}$ from the $\mathrm{AD}$ boundary, and mixed goethite and lepidocrocite in the region $10-25 \mathrm{~mm}$ away from the AD boundary, trends that are consistent with our experimental observations. Both model and experimental results presented herein establish that gradients in $\mathrm{Fe}^{2+}$ concentration within diffusion-controlled pore regimes can result in heterogeneous 
transformation of ferrihydrite to predominantly goethite and magnetite, with magnetite limited to the areas where high concentrations of $\mathrm{Fe}(\mathrm{II})$ are rapidly produced.

The modeling results provide an explanation for the occurrence of lepidocrocite only at the distal end of the diffusion cell. Because magnetite promotes rapid conversion of lepidocrocite, it likely forms initially with the arrival of elevated $\mathrm{Fe}^{2+}$ (aq) concentrations but is then rapidly converted to goethite (or magnetite); this is illustrated in the early time simulations (Fig. 8). Only at the distal end of the diffusion cell, where elevated concentrations of $\mathrm{Fe}^{2+}$ (aq) have only recently arrived and magnetite is absent, is lepidocrocite observed.

These experimental and modeling results also illustrate the importance of initial conditions in dictating reaction pathway. Moreover, the reaction network utilized in the numerical simulations is shown to be robust; the model is able to reproduce results from both hydrostatic (batch) experiments and those in the diffusion cells under variable dissolved $\mathrm{Fe}^{2+}$ concentrations without altering any reaction rate expressions. Where $\mathrm{Fe}^{2+}{ }_{(\mathrm{aq})}$ concentrations are initially high, magnetite is observed. However, further down the diffusive gradient, where initial $\mathrm{Fe}^{2+}$ concentrations are low, magnetite is not observed, even after $\mathrm{Fe}^{2+}$ concentrations exceed 1 $\mathrm{mM}$. The initial formation of goethite inhibits subsequent magnetite formation principally by removing tetrahedral $\mathrm{Fe}(\mathrm{III})$ centers in ferrihydrite that are presumed essential for $\mathrm{Fe}(\mathrm{II})$ induced nucleation of magnetite.

Consistent both with model simulations and with mineralogical transformations observed previously in both hydrostatic and hydrodynamic systems, our results outline a strong relationship between $\mathrm{Fe}^{2+}$ concentration (expressed by distance into micropore) and formation of secondary iron (hydr)oxides (Fredrickson et al., 1998; Benner et al., 2002; Zachara et al., 2002; Hansel et al., 2003). This work demonstrates the potential for dramatic spatial variability in 
secondary mineral phase products following reduction of ferrihydrite in diffusion dominated systems and provides a model for expanding these observations to soil and other natural systems exhibiting physical and biogeochemical heterogeneity.

\section{ACKNOWLEDGEMENTS}

The operations of the Advanced Light Source at Lawrence Berkeley National Laboratory are supported by the Director, Office of Science, Office of Basic Energy Sciences, U.S. Department of Energy under contract number DE-AC02-05CH11231. Portions of this research were carried out at the Stanford Synchrotron Radiation Laboratory, a national user facilities operated by Stanford University on behalf of the U.S. Department of Energy, Office of Basic Energy Sciences under contract DE-AC02-06CH11357. Support was also provided by U.S. Department of Energy, Office of Biological and Environmental Research, Environmental Remediation Sciences Program (contract no. DE-AC02-05CH11231) and the Stanford NSF Environmental Molecular Sciences Institute (NSF-CHE-0431425). 


\section{REFERENCES}

Allison, J.D., D.S. Brown, and K.J. Novo-Gradac 1991 MINTEQA2/PRODEFA2 A

Geochemical Assessment Model for Environmental Systems: Version 3.0 User's Manual. United States Environmental Protection Agency, Office of Research and Development, Washington, DC, EPA/600/3-91/021, 106.

Bai, M. and J. C. Roegiers (1997). "Triple-porosity analysis of solute transport." J. Contam. Hydrol. 28(3): 247-266.

Bekins, B. A., I. M. Cozzarelli, E. M. Godsy, E. Warren, H. I. Essaid and M. E. Tuccillo (2001). "Progression of natural attenuation processes at a crude oil spill site: II. Controls on spatial distribution of microbial populations." J. Contam. Hydrol. 53(3-4): 387-406.

Benner, S., C. Hansel, B. Wielinga, T. Barber and S. Fendorf (2002). "Reductive dissolution and biomineralization of iron hydroxide under dynamic flow conditions." Environ. Sci. Technol. 36(8): 1705-1711.

Borch, T., Y. Masue, R. K. Kukkadapu and S. Fendorf (2007). "Phosphate imposed limitations on biological reduction and alteration of ferrihydrite." Environ. Sci. Technol. 41(1): 166172.

Brzezinska, M., Z. Stepniewska and W. Stepniewski (1998). "Soil oxygen status and dehydrogenase activity." Soil Biol. Biochem. 30(13): 1783-1790.

Bundt, M., F. Widmer, M. Pesaro, J. Zeyer and P. Blaser (2001). "Preferential flow paths: Biological 'hot spots' in soils." Soil Biol. Biochem. 33(6): 729-738. 
Cornell, R. M. and U. Schwertmann (2003). The Iron Oxides, Wiley-VCH.

DeLemos, J. L., B. C. Bostick, C. E. Renshaw, S. Sturup and X. H. Feng (2006). "Landfillstimulated iron reduction and arsenic release at the Coakley Superfund Site (NH)." Environ. Sci. Technol. 40(1): 67-73.

Fischer, W. R. (1972). Die Wirkung von Zweiwertigem Eisen Auflosung und Umwandlung von Eisen(III)-hydroxiden. Trans. Comm. V \& VI Int. Soil Sci. Soc. E. Schlichting and U. Schwertmann. Weinheim, VCH: 37-44.

Fredrickson, J., J. Zachara, D. Kennedy, H. Dong, T. Onstott, N. Hinman, et al. (1998). "Biogenic iron mineralization accompanying the dissimilatory reduction of hydrous ferric oxide by a groundwater bacterium." Geochim. Cosmochim. Ac. 62(19-20): 3239-3257.

Gorby, Y. A. and D. R. Lovley (1991). "Electron transport in the dissimilatory iron reducer, GS15." Appl. Environ. Microb. 57(3): 867-870.

Grisak, G. E. and J. F. Pickens (1980). "Solute transport through fractured media. I. The effect of matrix diffusion." Water Resour. Res. 16(4): 719-30.

Hansel, C. M., S. G. Benner and S. Fendorf (2005). "Competing Fe(II)-induced mineralization pathways of ferrihydrite." Environ. Sci. Technol. 39(18): 7147-7153.

Hansel, C. M., S. G. Benner, J. Neiss, A. Dohnalkova, R. K. Kukkadapu and S. Fendorf (2003). "Secondary mineralization pathways induced by dissimilatory iron reduction of ferrihydrite under advective flow." Geochim. Cosmochim. Ac. 67(16): 2977-2992.

Harvey, J. W. and W. K. Nuttle (1995). "Fluxes of water and solute in a coastal wetland sediment: 2. Effect of macropores on solute exchange with surface water." J. Hydrol. 164(1-4): 109-125. 
Johnson, W. M., J. E. McClelland, S. B. McCaleb, R. Ulrich, W. G. Harper and T. B. Hutchings (1960). "Classification and Description of Soil Pores." Soil Sci. 89: 319-321.

Jurjovec, J., D. W. Blowes, C. J. Ptacek and K. U. Mayer (2004). "Multicomponent reactive transport modeling of acid neutralization reactions in mine tailings." Water Resour. Res. 40(11): W1120201-W1120217.

Kukkadapu, R. K., J. M. Zachara, J. K. Fredrickson, S. C. Smith, A. C. Dohnalkova and C. K. Russell (2003). "Transformation of 2-line ferrihydrite to 6-line ferrihydrite under oxic and anoxic conditions." Am. Mineral. 88(11-12): 1903-1914.

Langmuir, Donald, 1969, The Gibbs free energies of substances in the system Fe-O2-H2O-CO2 at $25^{\circ}$ in Geological Survey Research 1969: U. S. Geological Survey Professional Paper 650-B, p. B180-B183.

Lovley, D. R. (1997). "Microbial Fe(III) reduction in subsurface environments." FEMS Microbiol. Rev. 20(3-4): 305-313.

Luxmoore, R. J. (1981). "Microporosity, Mesoporosity, and Macroporosity of Soil." Soil Sci. Soc. Am. J. 45(3): 671-672.

Marshall, T. J. (1959). Relations between Water and Soil, Farnham Royal, UK.

Mayer, K. U., E. O. Frind and D. W. Blowes (2002). "Multicomponent reactive transport modeling in variably saturated porous media using a generalized formulation for kinetically controlled reactions." Water Resour. Res. 38(9): 1174.

Nealson, K. H. and D. Saffarini (1994). Iron and manganese in anaerobic respiration: Environmental significance, physiology, and regulation. Annual Review of Microbiology. L. Ornston, Annual Reviews Inc.: 311-343. 
Neubauer, S. C., D. Emerson and J. P. Megonigal (2002). "Life at the energetic edge: Kinetics of circumneutral iron oxidation by lithotrophic iron-oxidizing bacteria isolated from the wetland-plant rhizosphere." Appl. Environ. Microb. 68(8): 3988-3995.

NIST 46. National Institute of Standards and References, NIST Standard Reference Database 46, http://www.nist.gov/srd/nist46.htm

Parker, B. L., R. W. Gillham and J. A. Cherry (1994). "Diffusive disappearance of immisciblephase organic liquids in fractured geologic media." Ground Water 32(5): 805-819.

Parkin, T. B. (1987). "Soil Microsites as a Source of Denitrification Variability." Soil Sci. Soc. Am. J. 51(5): 1194-1199.

Pedersen, H. D., D. Postma and R. Jakobsen (2006). "Release of arsenic associated with the reduction and transformation of iron oxides." Geochim Cosmochim Ac 70(16): 41164129.

Postma, D. (1981). "Formation of Siderite and Vivianite and the Pore-Water Composition of a Recent Bog Sediment in Denmark." Chemical Geology 31(3): 225-244.

Robie, R. A., and Waldbaum, D. R., (1968). Thermodynamic properties of minerals and related substances at $298.15^{\circ} \mathrm{K}\left(25.0^{\circ} \mathrm{C}\right)$ and one atmosphere $(1.013$ bars $)$ pressure and at higher temperatures: U. S. Geological Survey Bulletin 1259, 256.

Roden, E. E. and J. M. Zachara (1996). "Microbial reduction of crystalline iron(III) oxides: Influence of oxide surface area and potential for cell growth." Env. Sci. Technol. 30(5): 1618-1628.

Salminen, J. M., P. J. Hanninen, J. Leveinen, P. T. J. Lintinen and K. S. Jorgensen (2006). "Occurrence and Rates of Terminal Electron-Accepting Processes and Recharge 
Processes in Petroleum Hydrocarbon-Contaminated Subsurface." J. Environ. Qual. 35(6): 2273-2282.

Schwertmann, U. and R. M. Cornell (1991). Iron Oxides in the Laboratory. New York, Weinheim.

Sobolev, D. and E. E. Roden (2001). "Suboxic deposition of ferric iron by bacteria in opposing gradients of Fe(II) and oxygen at circumneutral pH." Appl. Environ. Microb. 67(3): 13281334.

Steefel, C. I. and P. Van Cappellen (1990). "A new kinetic approach to modeling water-rock interaction - the role of nucleation, precursors, and Ostwald ripening." Geochim. Cosmochim. Ac. 54(10): 2657-2677.

Stumm, W. and J. Morgan (1996). Aquatic Chemistry. New York, Wiley.

Sudicky, E. A. and E. O. Frind (1982). "Contaminant Transport in Fractured Porous Media: Analytical Solutions for a System of Parallel Fractures." Water Resour. Res. 18(6): 16341642.

Tokunaga, T. K., J. Wan, M. K. Firestone, T. C. Hazen, E. Scwartz, S. R. Sutton, et al. (2001). "Chromium diffusion and reduction in soil aggregates." Env. Sci. Technol. 35: 31693174.

Tokunaga, T. K., J. Wan, J. Pena, E. L. Brodie, M. K. Firestone, T. C. Hazen, et al. (2005). "Uranium Reduction in Sediments under Diffusion-Limited Transport of Organic Carbon." Env. Sci. Technol.

Tokunaga, T. K., J. Wan, J. Pena, S. R. Sutton and M. Newville (2004). "Hexavalent Uranium Diffusion into Soils from Concentrated Acidic and Alkaline Solutions." Env. Sci. Technol. 38(11): 3056-3062. 
Webb, S. M. (2005). "Sixpack: A graphical user interface for XAS analysis using IFEFFIT." Phys. Scripta T115: 1011-1014.

Wilson, G. V., P. M. Jardine and J. P. Gwo (1992). "Modeling the hydraulic properties of a multi-region soil." Soil Sci. Soc. Am. J. 56: 1731-1737.

Zachara, J. M., R. K. Kukkadapu, J. K. Fredrickson, Y. A. Gorby and S. C. Smith (2002).

"Biomineralization of Poorly Crystalline Fe(III) Oxides by Dissimilatory Metal Reducing Bacteria (DMRB)." Geomicrobiol. J. 19: 179-207. 


\section{FIGURE CAPTIONS}

Fig. 1. Thermodynamic stability of iron (hydr)oxides shown as total activity of ferric iron in equilibrium with ferrihydrite, lepidocrocite and magnetite (assuming $2 \mathrm{mM} \mathrm{Fe}^{2+}$ ) as a function of pH. Grey arrow indicates dissolution/transformation pathway of ferrihydrite to lepidocrocite, goethite, and magnetite in order of thermodynamic favorability. Thin dashed lines on either side

of the magnetite solubility line indicate variations in magnetite solubility with aqueous $\mathrm{Fe}^{2+}$ concentrations of $0.2 \mathrm{mM} \mathrm{Fe}^{2+}$ (upper line) and $20 \mathrm{mM} \mathrm{Fe}^{2+}$ (lower line). Figure produced using MINTEQA2 database included in Visual Minteq v. 2.5.

Fig. 2. Schematic illustration of soil pore-scale heterogeneity. Development of $\mathrm{Fe}^{2+}$ gradients in diffusive domains, and postulated distribution of iron (hydr)oxides resulting from diffusive gradients.

Fig. 3. Schematic illustration showing parallel plate experimental setup.

Fig. 4. Observed and simulated temporal trends of ferrihydrite $(\mathrm{F})$ conversion to the secondary phases goethite $(\mathrm{G})$, lepidocrocite $(\mathrm{L})$, and magnetite $(\mathrm{M})$ as a function of $\mathrm{Fe}^{2+}$ concentration $(10$ mM PIPES, pH 7.2). Upper panels show percentages ( \pm 5 mol \%) determined from linear combination fits of $\mathrm{k}^{3}$-weighted Fe EXAFS spectra $\left(\mathrm{k}=1-14 \AA^{-1}\right)$ with a detection limit of $c a .5$ \%. (Data from Hansel et al, 2005); lower panels show modeled data simulated using MIN3P. 
Fig. 5. Iron (hydr)oxide distribution map illustrates goethite (blue), magnetite (green) and ferrihydrite (red) (A), summary of mineral phase distribution based on linear combination fitted EXAFS data (B), and simulated mineral distribution (C) on the surface of reacted (21 d) ferrihydrite coated parallel lexan plates. Iron (hydr)oxides shown include ferrihydrite (F), goethite $(\mathrm{G})$, magnetite $(\mathrm{M})$, and lepidocrocite $(\mathrm{L})$.

Fig. 6. Experimentally acquired Fe-EXAFS spectra (solid line) with selected least squares fits obtained from reacted parallel plate surface coatings (A) and summary of resulting solid phase distrbutions with distance along the diffusion cell (B).

Fig. 7. Simulated concentrations of ferrous iron (dashed lines) and sulfate (solid lines) after 1, 10 , and $21 \mathrm{~d}$ as a function of depth within the reacting parallel plate.

Fig. 8. Simulated distribution of ferrihydrite, goethite, magnetite and lepidocrocite within the reacting parallel plate after $1,5,10$, and $21 \mathrm{~d}$. 
Table 1. Iron (hydr)oxide Solubility Products used in MIN3P Simulations

\begin{tabular}{ccc}
\hline Mineral and Reaction Expression & log K & Source \\
\hline $\begin{array}{c}\text { Ferrihydrite } \\
\mathrm{Fe}^{3+}+3 \mathrm{H}_{2} \mathrm{O} \Rightarrow \mathrm{Fe}(\mathrm{OH})_{3(s)}+3 \mathrm{H}^{+}\end{array}$ & -4.8910 & Langmuir, 1969 \\
\hline Goethite & 1.000 & NIST 46 \\
\hline $\mathrm{Fe}^{3+}+2 \mathrm{H}_{2} \mathrm{O} \Rightarrow \mathrm{FeOOH}$ \\
\hline $\begin{array}{c}\text { Lepidocrocite } \\
\mathrm{Fe}^{3+}+2 \mathrm{H}_{2} \mathrm{O} \Rightarrow \mathrm{FeOOH}_{(s)}+3 H^{+}\end{array}$ & -1.371 & Allison et al., 1991 \\
\hline $\begin{array}{l}\text { Magnetite } \\
2 \mathrm{Fe}^{3+}+\mathrm{Fe}^{2+}+4 \mathrm{H}_{2} \mathrm{O} \Rightarrow \mathrm{Fe}_{3} \mathrm{O}_{4(s)}+8 H^{+}\end{array}$ & -3.737 & Robie and Waldbaum 1968
\end{tabular}




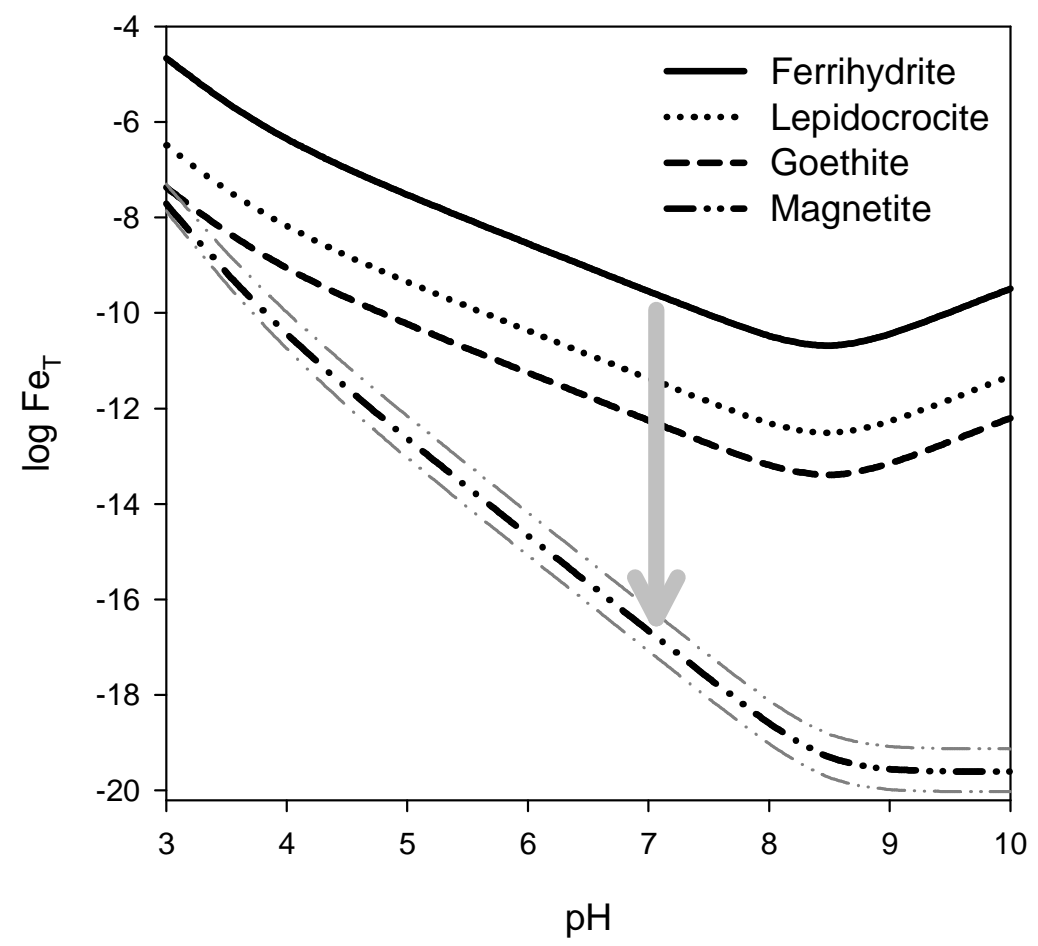

Fig. 1. Thermodynamic stability of iron (hydr)oxides shown as total activity of ferric iron in equilibrium with ferrihydrite, lepidocrocite and magnetite (assuming $2 \mathrm{mM} \mathrm{Fe}^{2+}$ ) as a function of $\mathrm{pH}$. Grey arrow indicates dissolution/transformation pathway of ferrihydrite to lepidocrocite, goethite, and magnetite in order of thermodynamic favorability. Thin dashed lines on either side of the magnetite solubility line indicate variations in magnetite solubility with aqueous $\mathrm{Fe}^{2+}$ concentrations of $0.2 \mathrm{mM} \mathrm{Fe}^{2+}$ (upper line) and $20 \mathrm{mM} \mathrm{Fe}^{2+}$ (lower line). Figure produced using MINTEQA2 database included in Visual Minteq v. 2.5. 

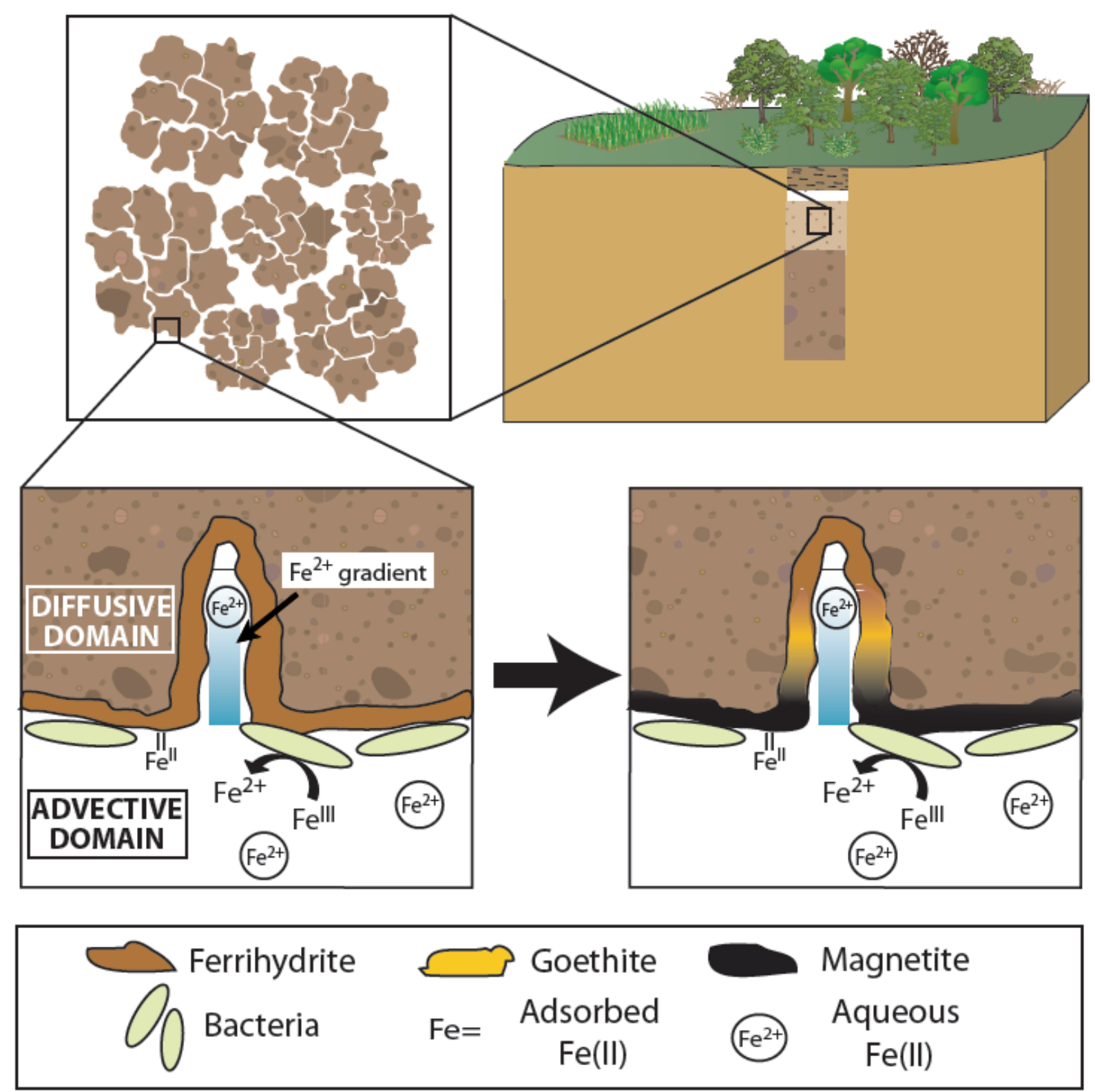

Fig. 2. Schematic illustration of soil pore-scale heterogeneity. Development of $\mathrm{Fe}^{2+}$ gradients in diffusive domains, and postulated distribution of iron (hydr)oxides resulting from diffusive gradients. 


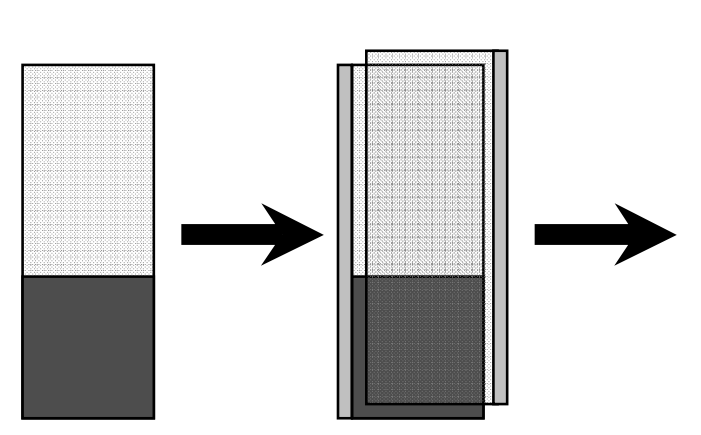

Lexan slide coated with ferrihydrite
Glass slide placed over ferrihydrite coated lexan \& sealed along vertical edges
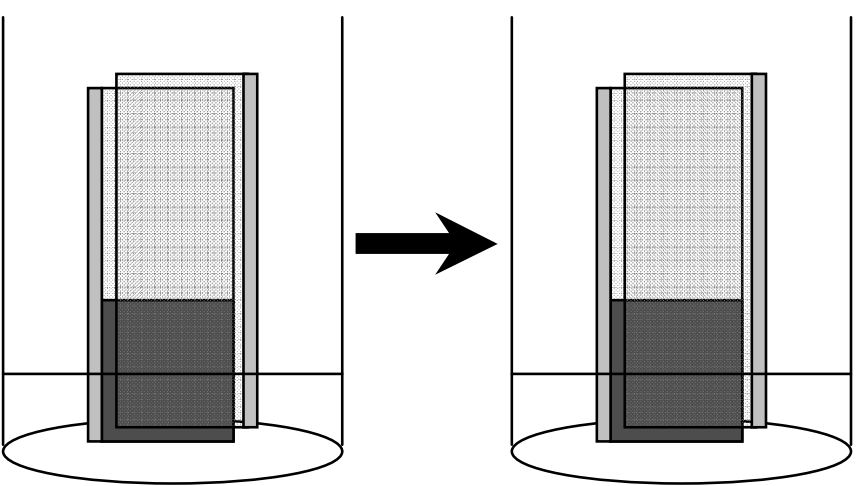

Parallel plates equilibrated with 16 mM PIPES to eliminate capillary effects
Equilibration solution replaced with $40 \mathrm{mM}$ $\mathrm{FeSO}_{4} / 16 \mathrm{mM}$ PIPES

Fig. 3. Schematic illustration showing parallel plate experimental setup. 

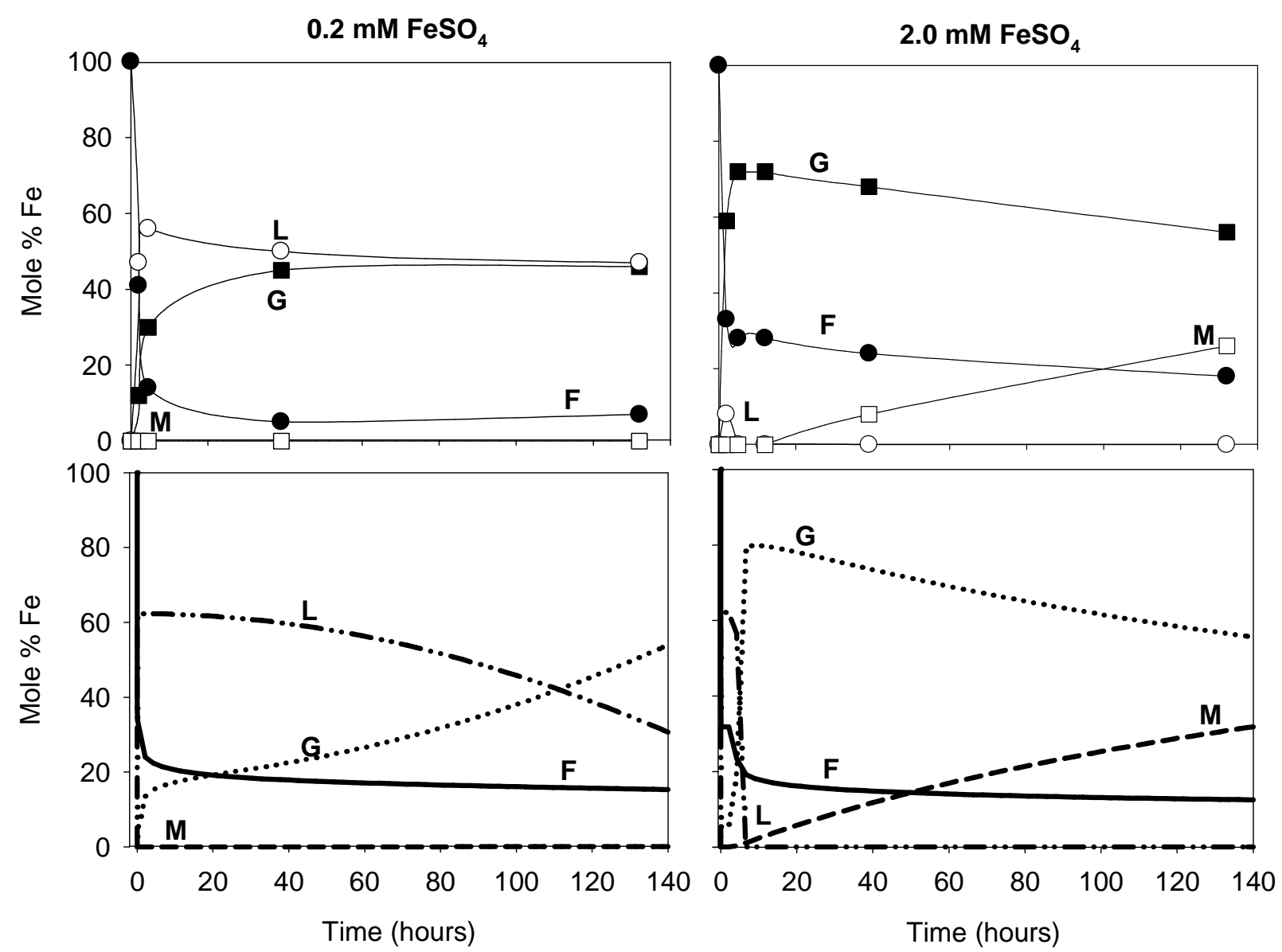

Fig. 4. Observed and simulated temporal trends of ferrihydrite $(F)$ conversion to the secondary

phases goethite $(\mathrm{G})$, lepidocrocite $(\mathrm{L})$, and magnetite $(\mathrm{M})$ as a function of $\mathrm{Fe}^{2+}$ concentration (10 mM PIPES, $\mathrm{pH}$ 7.2). Upper panels show percentages ( $\pm 5 \mathrm{~mol} \%)$ determined from linear combination fits of $\mathrm{k}^{3}$-weighted Fe EXAFS spectra $\left(\mathrm{k}=1-14 \AA^{-1}\right)$ with a detection limit of $c a .5$ \%. (Data from Hansel et al, 2005); lower panels show modeled data simulated using MIN3P. 

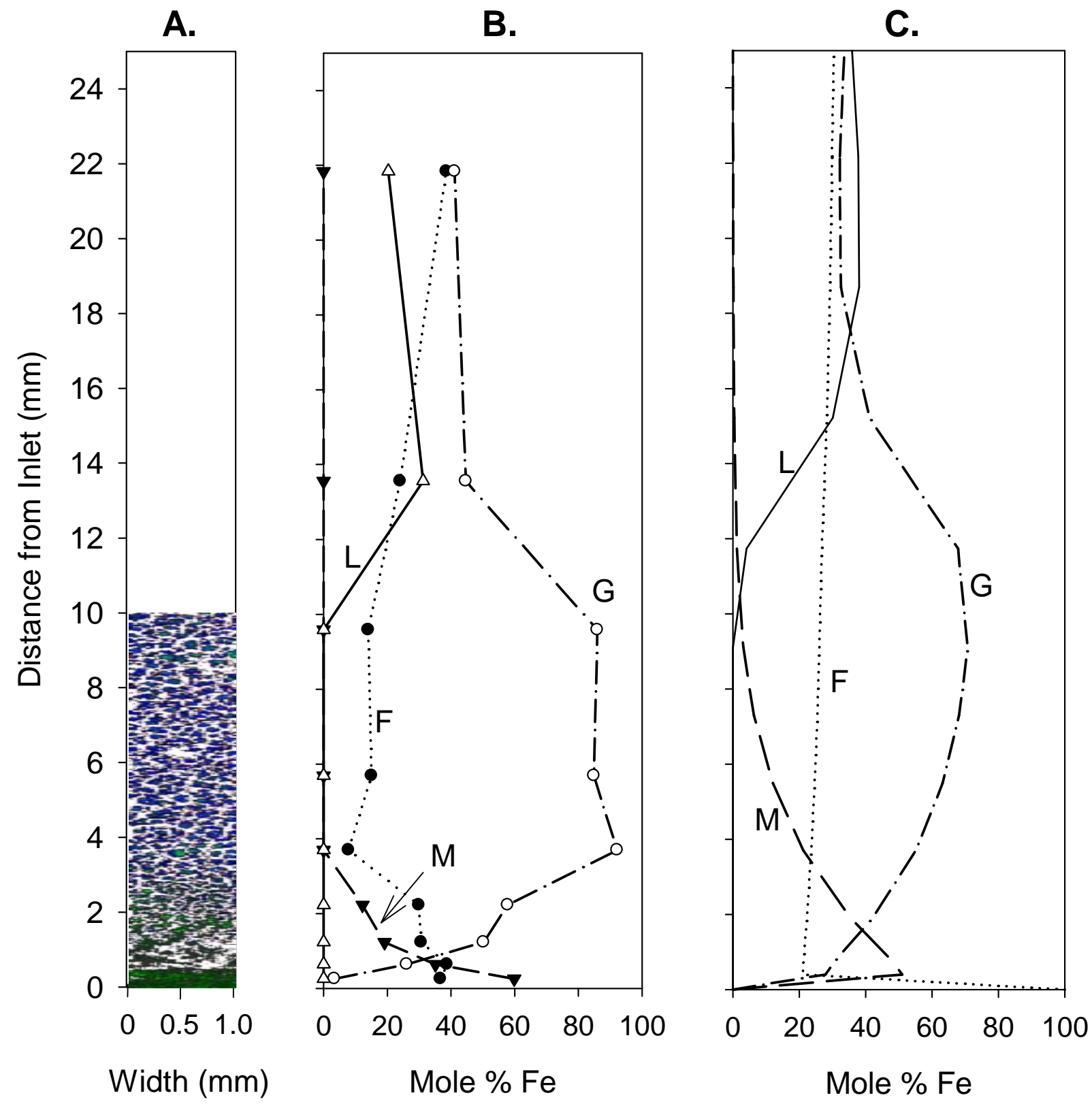

Fig. 5. Iron (hydr)oxide distribution map illustrates goethite (blue), magnetite (green), and ferrihydrite (red).(A), summary of mineral phase distribution based on linear combination fitted EXAFS data (B), and the MIN3P simulated mineral distribution (C) on the surface of reacted (21 d) ferrihydrite coated parallel lexan plates. Iron (hydr)oxides shown include ferrihydrite (F), goethite $(\mathrm{G})$, magnetite $(\mathrm{M})$, and lepidocrocite (L). 

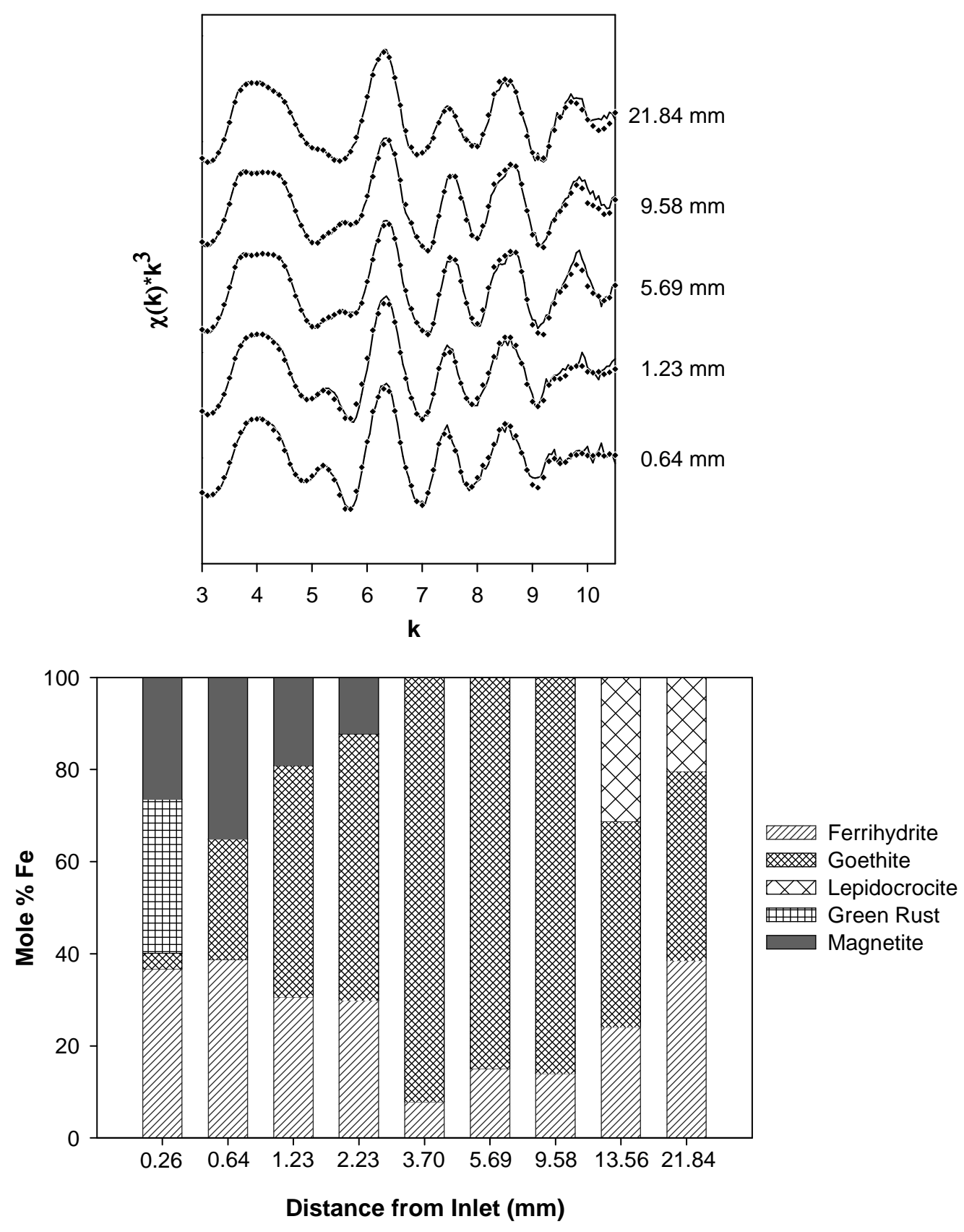

Fig. 6. Experimentally acquired Fe-EXAFS spectra (solid line) with selected least squares fits obtained from reacted parallel plate surface coatings (A) and summary of resulting solid phase distributions with distance along the diffusion cell (B). 


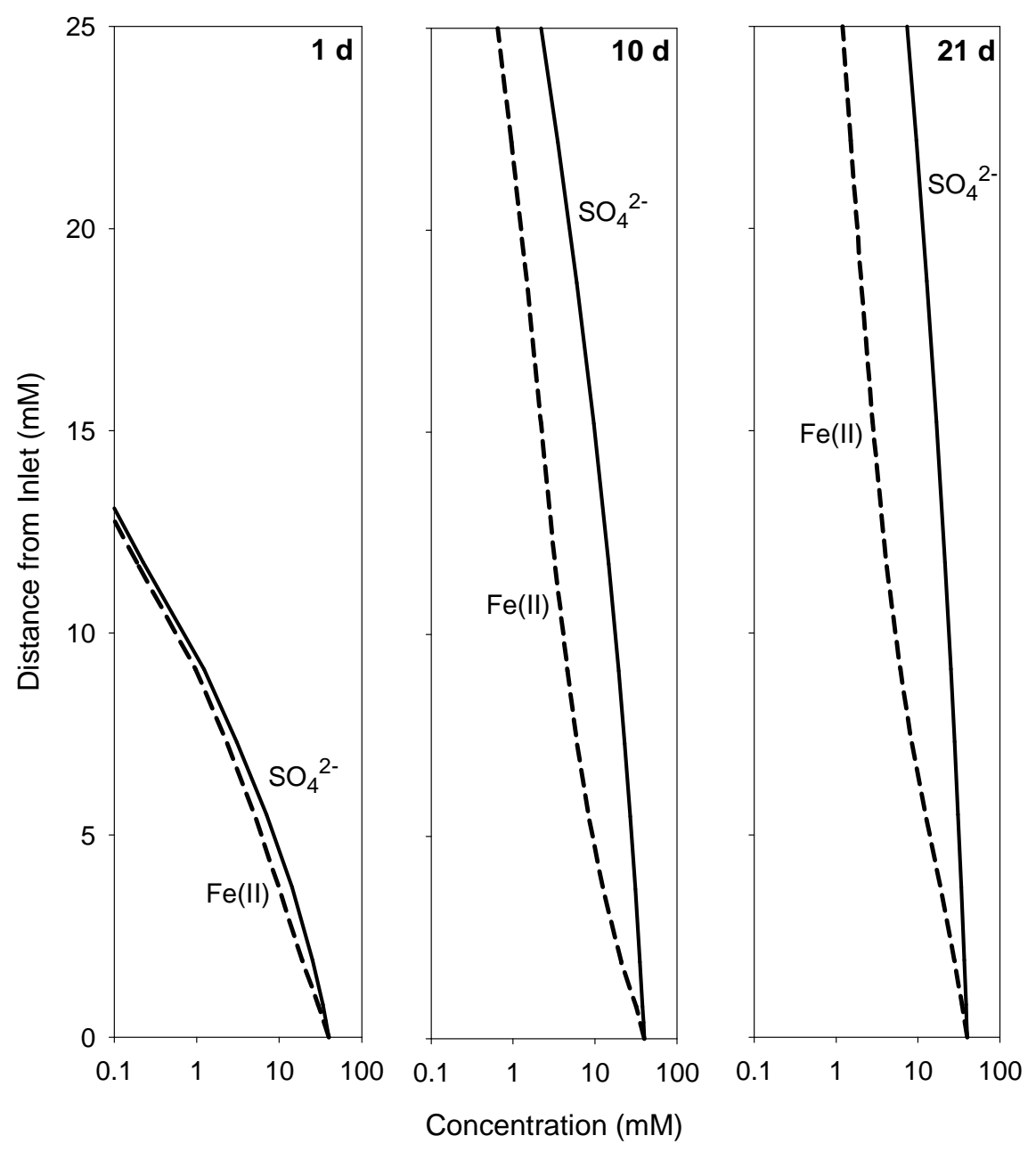

Fig. 7. Simulated concentrations of ferrous iron (dashed lines) and sulfate (solid lines) after 1, 10 , and $21 \mathrm{~d}$ as a function of depth within the reacting parallel plate. 

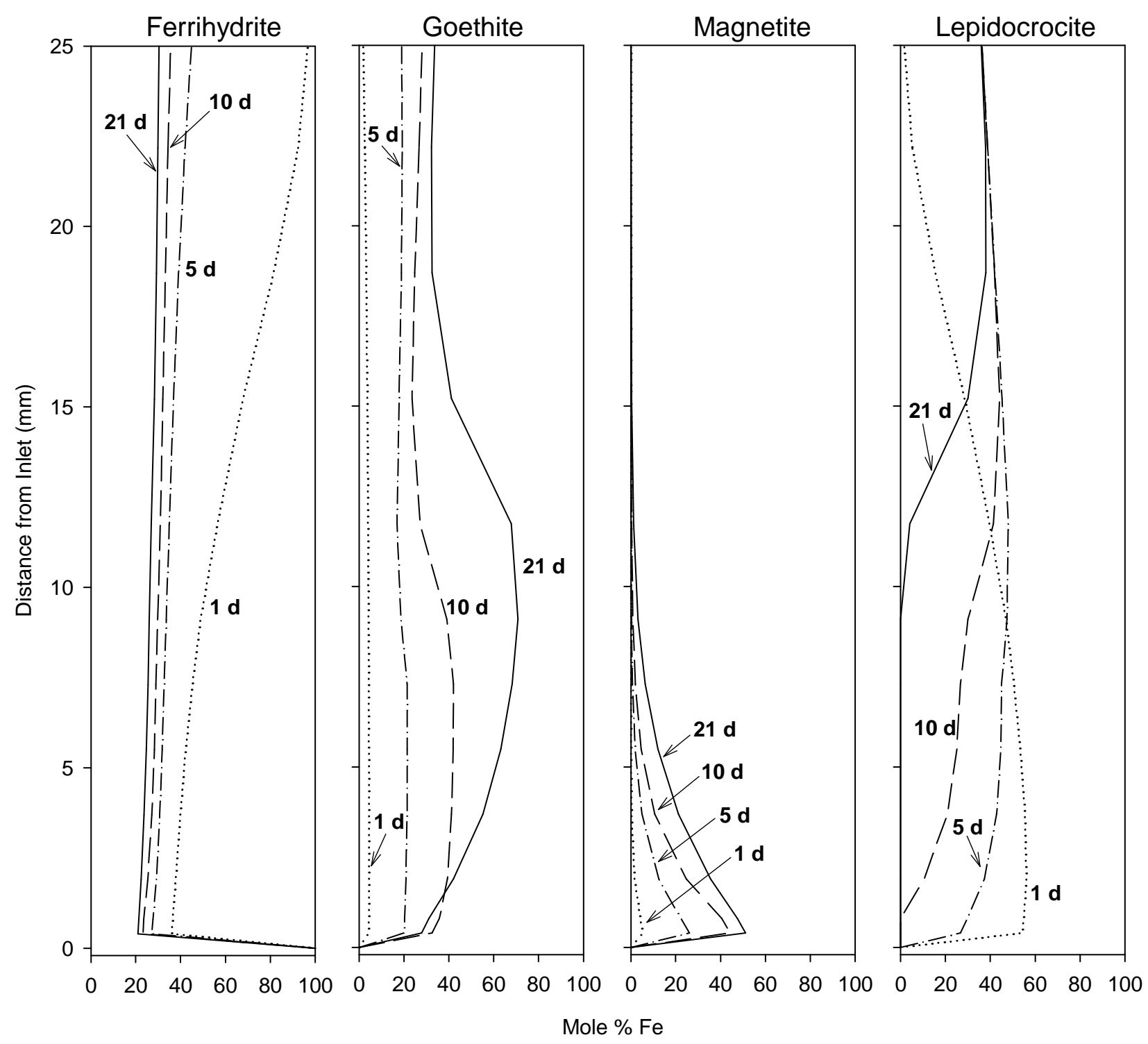

Fig. 8. Simulated distribution of ferrihydrite, goethite, magnetite and lepidocrocite within the reacting parallel plate after $1,5,10$, and $21 \mathrm{~d}$. 